\title{
PADRÕES ESTATÍSTICOS DO ENCAIXAMENTO DA MUDANÇA DE SE-PASSIVO A SE-INDEFINIDO NA HISTÓRIA DO PORTUGUÊS
}

\author{
Silvia Regina de Oliveira CAVALCANTE*
}

- RESUMO: Este trabalho traz uma análise das construções tradicionalmente classificadas como passivas sintéticas, em comparação com construções passivas analíticas e outras construções com SE (inerente, reflexivo, recíproco, etc.) em textos de autores portugueses nascidos entre os séculos XVI e XIX. O objetivo principal é mostrar, através da comparação do padrão de ordem dos "sujeitos" dessas construções, a evolução da mudança linguística que afetou a posição do sujeito e pode ter afetado as construções passivas sintéticas. Segundo Galves e Paixão de Sousa (2005, 2010), o Português Clássico (séculos XVI e XVII) caracteriza-se por ser uma gramática em que a posição à esquerda do verbo é uma posição para onde se movem os constituintes topicalizados, incluindo aí os sujeitos; assim, a posição de base do sujeito é a pós-verbal. A partir do século XVIII, ocorre uma mudança em que a posição do sujeito passa a ser a pré-verbal e os elementos topicalizados ocupam a periferia à esquerda. Com base nesse quadro, este trabalho demonstra através da análise quantitativa da evolução dessas três construções ao longo do tempo que a mudança que ocorre nas construções com SE de passivo a indefinido - pode ter sido desencadeada pela mudança na posição do sujeito.

- PALAVRAS-CHAVE: Sintaxe histórica quantitativa. Mudança encaixada. Posição do sujeito. Passivas. Construções com SE.

\section{Apresentação}

Nas línguas românicas, as construções com SE, mais especificamente as conhecidas construções "passivas sintéticas", apresentam um desafio para a teoria sintática no que diz respeito à posição de sujeito e a checagem de Caso, por causa do padrão de concordância que aparece nessas construções: o argumento interno pode desencadear a concordância com o verbo, como vemos em (1). ${ }^{1}$ A maioria dos trabalhos dentro da Teoria de Regência e Ligação (MANZINI, 1986; CINOUE, 1988; DOBROVIE-SORIN, 1998; MATEUS et al., 2003; CYRINO, 2007) defendem que essas construções sejam consideradas passivas, e se assemelham às construções inacusativas, em que o argumento interno recebe o Caso Nominativo e ocupa

* UFRJ - Universidade Federal do Rio de Janeiro. Faculdade de Letras. Rio de Janeiro - RJ - Brasil. 21941-917 silviare@gmail.com

1 De acordo com as análises consultadas, as sentenças de (1) a (3) seriam possíveis tanto no Português Europeu (PE) quanto no Português Brasileiro (PB). 
ou está ligado à posição de sujeito. Por outro lado, construções com SE com outros tipos de verbos (transitivos indiretos, inacusativos, inergativos, cópula etc.) e com verbos transitivos diretos que não apresentam concordância com o argumento interno, como nos exemplos em (2) e (3), respectivamente, são consideradas exemplos de SE-nominativo, em que o clítico SE absorve o Caso Nominativo e o argumento interno o Caso Acusativo. Podemos perceber que é o padrão de concordância que aparece quando o argumento interno é plural que é utilizado como critério para definir se se trata de uma construção de se-passivo ou se-nominativo.

(1) Vendem-se casas.

(2) a. Precisa-se de empregados

b. Vive-se bem no Rio de Janeiro.

(3) Vende-se casas.

Na diacronia do português, podemos observar casos em que o argumento externo aparece como um sintagma preposicionado, o que no português contemporâneo, tanto $\mathrm{PE}$ quanto $\mathrm{PB}$, não é mais gramatical, como vemos com o contraste entre (4a), um exemplo de Manuel da Costa, autor nascido em 1601, e (4b):

(4) a. "Os mais guerreiros Reys do mundo se ajudaraõ de estranhos" (CORPUS..., 2011). b. *Vendem-se casas pela imobiliária. ${ }^{2}$

Por outro lado, análises dentro do quadro teórico Minimalista, como as de Raposo e Uriagereka (1996) para o PE e de D'Alessandro (2007) para o italiano, propõem tratar essas construções como sendo construções ativas em que o DP argumento interno é um objeto que apresenta concordância com o verbo e o clítico SE ocupa a posição de sujeito.

Neste trabalho, recorro a uma análise quantitativa com base em dados extraídos de textos de autores nascidos entre os séculos XVI e XIX que compõem o Corpus Histórico Anotado do Português - O Corpus Tycho Brahe (CTB) - para defender que a mudança atestada para a posição do sujeito (GALVES; PAIXÃO DE SOUSA, 2005, 2010) desencadeou uma mudança na interpretação dos enunciados com SE: de passivo a indefinido. Minha hipótese principal é que, se essas construções com SE são construções passivas e se o argumento interno, pelo fato de desencadear a concordância com o verbo, é o sujeito, vamos observar padrões

2 A sentença (4b) pode ser aceitável no PB se se considerar a preposição por no sentido de através: "Vendem-se casas através da imobiliária". Entretanto, se se considerar por como uma preposição que marca papel temático de AGENTE do verbo, a sentença é agramatical, tanto no PB quanto no PE. 
semelhantes entre as construções passivas analíticas e o DP argumento interno vai apresentar um padrão semelhante aos DPs sujeitos de outras construções. Para defender essa hipótese, recorro a uma metodologia que alia o aparato formal da teoria sintática e o aparato quantitativo de análise estatística, cunhada por A. Kroch como "sintaxe histórica quantitativa". O aparato teórico por trás das hipóteses diz respeito a dois pontos: (1) a mudança atestada na história do português com relação à posição do sujeito (GALVES; PAIXÃO DE SOUSA, 2005, 2010) e (2) a análise das construções com SE, geralmente analisadas como passivas sintéticas, como construções ativas (RAPOSO; URIAGEREKA, 1996; D'ALESSANDRO, 2007).

Com relação à posição do sujeito, Galves e Paixão de Sousa $(2005,2010)$ defendem, a partir da análise de dados extraídos dos textos do CTB, que no Português Clássico (PCl) (séculos XVI e XVII) a posição à esquerda do verbo é uma posição para onde se movem constituintes topicalizados, incluindo os sujeitos. Só na gramática no Português Europeu (que pode ser encontrada nos textos de autores nascidos a partir do século XVIII) é que a posição do sujeito é pré-verbal e para a periferia esquerda se movem os constituintes topicalizados. As autoras propõem essa análise com base nas frequências dos padrões de ordem Sujeito-Verbo atestados nos referidos textos: até o século XVIII a frequência de VS é superior a SV; a partir do século XVIII, a frequência de SV supera a de VS.

Desse modo, considero aqui os seguintes pontos para a análise:

(a) A comparação do comportamento das construções com SE-passivo/SE-indefinido, construções com SE não passivo (reflexivo, inerente, ergativo) e construções passivas analíticas, principalmente com relação à ordem do DP argumento interno (ou não) em relação ao verbo flexionado.

(b) O comportamento de DPs sujeitos ao longo da história do português; com base nos resultados de Galves e Paixão de Sousa $(2005,2010)$ e com base no comportamento do DP sujeito das construções passivas analíticas (MELO, 2010; CAVALCANTE, 2009).

A hipótese principal que norteia este trabalho está centrada em outras mudanças que ocorreram na diacronia do português e que fazem levantar a existência de uma mudança gramatical ocorrida a partir da virada do século XVIII (se considerarmos a data de nascimento dos autores e não a da produção dos textos) que afeta a posição do sujeito, e afeta as construções "passivas sintéticas", desencadeando uma reanálise sintática dessas construções. ${ }^{3}$ Pretendo mostrar

\footnotetext{
Vale mencionar que outras pesquisas desenvolvidas a partir da análise de dados extraídos do Corpus Tycho Brahe têm mostrado que o século XVIII é o ponto em que emerge a gramática do $\mathrm{PE}$, com relação a fenômenos totalmente distintos, como, por exemplo, o padrão de colocação pronominal (GALVES; BRITTO; PAIXÃO DE SOUSA, 2005), o uso de artigo diante de possessivos (FLORIPI, 2008), as construções com SE (CAVALCANTE, 2006; ANTONELLI, 2008), o fenômeno da interpolação (NAMIUTI, 2008), a topicalização e o efeito V2 (GIBRAIL, 2010; GALVES; PAIXÃO DE SOUSA, 2005, 2010).
} 
que os padrões estatísticos de anteposição e posposição do DP "sujeito" são consequência (a) das diferenças envolvidas na mudança que ocorre do PCl para PE; (b) da mudança do SE-passivo para o SE-indefinido; (c) da mudança na posição do sujeito. Desse modo, as seguintes predições podem ser feitas envolvendo as diferenças entre o $\mathrm{PCl}$ e o $\mathrm{PE}$ :

(1) Entre os séculos XVI e XVII, as frequências de anteposição e posposição dos argumentos sujeitos de todas as construções serão semelhantes, com preferência pela posposição, tendo em vista que a posição básica do sujeito é a pós-verbal.

(2) A partir do século XVIII, os índices de sujeito anteposto vão superar os índices de sujeito posposto, fazendo com que dois padrões se apresentem: os sujeitos das passivas analíticas e das construções com SE não passivo se tornam preferencialmente antepostos, ao passo que nas outras construções com SE, o DP argumento interno será preferencialmente posposto, pois estamos diante de construções com SE-indefinido.

Em primeiro lugar, apresento duas propostas de análise das construções ditas passivas sintéticas do ponto de vista teórico abarcando pelo menos dois modelos teóricos: a Teoria de Regência e Ligação e o Programa Minimalista; em seguida, apresento a análise quantitativa dos dados que comprova empiricamente as hipóteses levantadas aqui; e finalmente, apresento a análise do encaixamento da mudança.

\section{A dita passiva sintética é uma passiva?}

Os anos 1980 caracterizaram-se por uma explosão de análises gerativistas comparativas em busca das características da Gramática Universal e uma quebra em relação ao Modelo Padrão ou Padrão Estendido. Com relação às construções tradicionalmente consideradas passivas sintéticas, não foi diferente: vários estudos dentro do Modelo de Regência e Ligação (CHOMSKY, 1986) deram conta do fenômeno como sendo um caso semelhante às construções passivas, ou mesmo às inacusativas, não se afastando, portanto, da ideia transmitida durante séculos pela Tradição Gramatical. Dentro do Modelo de Regência e Ligação, podemos mencionar as análises de Manzini (1986); Cinque (1988); Mendikoetxea (1990); Nunes (1990); Dobrovie-Sorin (1998); Otero (1999), entre outros. Por outro lado, dentro do Programa Minimalista, Raposo e Uriagereka (1996) para o PE e D'Alessandro (2007) para o Italiano propõem uma abordagem diferente que se desvincula tanto da Tradição Gramatical quanto das abordagens gerativistas anteriores, no sentido de analisarem o SE como sendo o elemento que ocupa a posição de sujeito e o argumento interno como sendo um objeto que desencadeia a concordância com o verbo. 
Nesta seção, apresento, em primeiro lugar, uma discussão das propostas teóricas para a questão e as limitações do modelo de Regência e Ligação com base na literatura gerativista produzida principalmente nos anos 1980 e 1990; em seguida, apresento uma "solução" dentro do Programa Minimalista (RAPOSO; URIAGEREKA, 1996) que eu adoto para a análise dos dados.

Desconsiderando que, semanticamente, uma "passiva sintética" não corresponde a uma passiva analítica, tanto a análise das Gramáticas Tradicionais quanto as análises dentro do modelo de Regência e Ligação (CHOMSKY, 1986) as consideram construções passivas. Mateus et al. (2003) diferenciam dois tipos de se: o passivo e o nominativo. Consideram a estrutura em (5) a seguir, como uma passiva de -se (MATEUS et al., 2003, p.531).

(5) a. "Os artigos publicaram-se propositadamente no último número da revista." b. " "O canivete usou-se para cortar o pão."

O se-passivo recebe o papel temático externo do verbo e ocupa a posição de especificador do SV. Esse clítico funciona como um morfema passivo, pois: "ele absorve (ou elimina) o traço casual acusativo do verbo, forçando o argumento interno directo deslocar-se para aceder ao Caso nominativo" (MATEUS et al. 2003, p.532). As construções com se-passivo, se assemelham, portanto, tanto às construções passivas como às construções inacusativas, em que o argumento interno do verbo não pode receber acusativo e tem que receber nominativo, o que explica a concordância entre o verbo e seu argumento interno.

No caso das construções com argumento interno singular, Mateus et al. (2003, p.533) as consideram enunciados ambíguos entre uma interpretação passiva com se-passivo, ou ativa com se-nominativo, como vemos com os exemplos em (6):

(6) a. "Descobriu-se uma fuga no reactor nuclear." Int1: Foi descoberta uma fuga no reactor nuclear. Int2: Alguém descobriu uma fuga no reactor nuclear.

b. "Assaltou-se uma carrinha de transporte de valores." Int1: Foi assaltada uma carrinha de transporte de valores. Int2: Alguém assaltou uma carrinha de transporte de valores.

A construção passiva com se-passivo, ao contrário das passivas sintáticas, não permite a expressão do agente por um sintagma por, apesar de este agente receber uma interpretação arbitrária, como exemplificado em (7):

(7) a. * Os artigos publicaram-se no último número da revista pelo editor.

b. '* O canivete usou-se por alguém para cortar o pão. 
Sobre o se-nominativo, Mateus et al. (2003, p.836, grifo do autor) o consideram um clítico argumental de referência arbitrária, e acrescentam: "o sujeito associado a esse clítico é interpretado como indefinido e não específico, sendo parafraseável por expressões nominais como alguém". Os exemplos a seguir demonstram algumas características do se-nominativo. Em (8), encontramos exemplos de se com verbos transitivos sem o seu argumento interno ou apresentando a não concordância, ou com verbos inergativos. Os exemplos em (9) mostram que o se nominativo não pode ocorrer associado a uma posição de expletivo. E, finalmente, (10) mostra que o caráter referencial de se-nominativo possibilita o seu aparecimento em contextos de extração simultânea de clítico (MATEUS et al., 2003, p.837):

(8) a. "A grande questão está naquilo em que se acredita."

b. "Aluga-se casas."

c. "Trabalha-se demais."

(9) a. "*Há-se muitos livros nesta biblioteca."

b. "* Parece-se a toda a gente que os professores compram livros em excesso."

(10) "Informa-se que se aluga apartamentos e vende moradias."

Trata-se, portanto, de dois pronomes distintos: um que desempenha um papel sintático - o se-passivo - e o outro um elemento lexical - o se-nominativo. O se-passivo "transforma" o verbo transitivo em um verbo inacusativo, quando, por absorver o papel temático externo do verbo transitivo, o impede de atribuir Caso acusativo ao seu argumento interno. Assim, o argumento interno tem que receber Caso nominativo - como o argumento interno de verbos inacusativos. $\mathrm{O}$ se-nominativo, ao contrário, é um elemento lexical que contém traço [+humano, -definido] que faz com que a interpretação do sujeito da sentença seja arbitrária. Segundo a abordagem de Mateus et al. (2003), o se-passivo não é um argumento, se comporta como um morfema passivo, transforma a voz verbal; ao passo que o se-nominativo é um elemento que ocupa a posição de sujeito, um argumento.

A análise para o SE-passivo, se considerada uma passiva, apresenta um problema teórico na medida em que pressupõe que o argumento interno, que preferencialmente ocorre na posição pós-verbal, deve receber Caso Nominativo ou estar coindexado com uma posição que receba o Caso Nominativo. A solução encontrada para lidar com esse problema foi a mesma encontrada para lidar com as construções inacusativas e passivas analíticas: o argumento interno do verbo se move para a posição de sujeito para receber o Caso nominativo (11) ou, quando posposto, está associado a um expletivo na posição de sujeito via CADEIA (12):4

4 Outro problema, também do ponto de vista teórico, seria a noção de CADEIA. Assim, se por um lado, o modelo de análise ficou uniforme, com a noção de movimento (mova alfa) que abarcou numa operação várias 
(11) a. A porta abriu.

b. A porta foi aberta.

c. A porta abriu-se.

(12) a. $\quad$ pro $_{\text {expl }}$ abriu a porta.

b. pro $_{\text {expl }}$ foi aberta a porta.

c. pro $_{\text {expl }}$ abriu-se a porta.

Esse tipo de análise iguala as três construções - inacusativa, passiva e construção com SE - como envolvendo o mesmo tipo de movimento e de atribuição de Caso, desconsiderando as diferenças existentes entre elas e que deveriam ser consideradas como indício de que se trata de construções sintáticas distintas: nas construções inacusativas (11a) e (12a), diferentemente das outras duas, não se pode interpretar um agente para a ação, mesmo sendo indeterminado, como é possível nas construções passivas e com SE. Por outro lado, as construções com SE não são interpretadas como passivas, pelo menos não no PE moderno (tampouco no Português Brasileiro).

Uma solução para esse problema é dada por Raposo e Uriagereka (1996, p.750) para o PE: as construções de SE com verbos transitivos que apresentam concordância com seu argumento interno plural, como vemos em (13), são na verdade estruturas ativas, como são as construções sem concordância (14) e não se trata, neste caso, de SE-passivo:

(13) a. " "Ontem compraram-se demasiadas salsichas no talho Sanzot."

b. " "Essas salsichas compraram-se ontem no talho Sanzot."

(14) "Compra-se sempre demasiadas salsichas no talho Sanzot."

Raposo e Uriagereka (1996) chamam as construções com concordância de SE-indefinido e as sem concordância de SE-genérico. O ponto-chave da sua argumentação de que a estrutura não é passiva, é que o DP argumento interno não está na posição sujeito ([Spec, T]), tampouco ligado a uma categoria vazia nessa posição, como tinha sido analisado na literatura gerativista sobre o tema. O problema, então, é como explicar a concordância. Sua análise divide-se, pois, em duas partes: a primeira em que eles levantam os dados empíricos para provar que o DP não se comporta como um sujeito e a segunda em que, se valendo da Teoria de Checagem de traços (CHOMSKY, 1995), demonstram como se dá a concordância. Raposo e Uriagereka (1996) demonstram que o DP, quando movido da posição de objeto, ocupa, na realidade, uma posição na periferia esquerda da sentença, uma posição de tópico. E os argumentos são os seguintes:

transformações distintas (de ativa para passiva, por exemplo), fez surgirem conceitos e noções que só se aplicam a determinadas construções, como a noção de CADEIA. 
Em sentenças infinitivas complemento de predicados adjetivos, um sujeito lexical pode ocupar a posição pré-verbal, tanto numa sentença ativa, quando passiva (15). Nas construções com SE-indefinido, o DP só pode ocupar a posição pós-verbal, e não pré-verbal (16), o que pode indicar que esse DP não está na posição de sujeito (RAPOSO; URIAGEREKA, 1996, p.754):

(15) a. " "Vai ser difícil os tribunais aceitarem os documentos."

b. "Vai ser difícil os documentos serem aceites."

(16) a. "Vai ser difícil aceitarem-se os documentos."

b. " "*Vai ser difícil os documentos aceitarem-se."

A assimetria que existe na construção com SE-indefinido nas sentenças infinitivas desaparece nas encaixadas finitas: (17) mostra que é possível o DP aparecer numa posição pré-verbal tanto na passiva quanto na construção com SE-indefinido. No entanto Raposo e Uriagereka (1996, p.755) mostram que, em sentenças encaixadas, é possível a presença de um tópico, somente em sentenças finitas e não em encaixadas infinitivas, como mostra (18):

(17) a. "Vai ser difícil que os documentos sejam aceites".

b. "Vai ser difícil que se aceitem os documentos".

(18) a. "Vai ser difícil que esses documentos, o tribunal (os) possa aceitar".

b. "*Vai ser difícil esses documentos, os tribunais aceitarem(-nos)".

Um outro conjunto de dados que mostra que o DP anteposto nas construções com SE-indefinido não ocupa a posição de sujeito, mas uma posição de tópico, refere-se às infinitivas complemento de verbos epistêmicos, como aparece nos constrastes a seguir (RAPOSO; URIAGEREKA, 1996, p.756-757):

(19) a. "Eu penso terem os soldados fuzilado os presos."

(20) a. " " Eu penso terem-se os presos fuzilado."

b. "Eu penso terem os presos sido fuzilados."

(21) a. " "Eu penso terem sido fuzilados os presos."

b. "Eu penso terem-se fuzilado os presos."

O exemplo (19) mostra que um DP sujeito pode ocorrer à direita do verbo auxiliar, que no caso em questão, sobe para um núcleo acima de T. Já o DP na construção SE-indefinido não pode ocorrer nessa posição, ao passo que o DP sujeito de uma passiva pode, como mostra o contraste em (20). Como (21) mostra, o DP argumento interno pode ocorrer na posição de objeto tanto nas construções passivas, quanto na de SE-indefinido. 
Um outro argumento está relacionado à questão dos "nomes nus" (RAPOSO; URIAGEREKA, 1996: 760). No PE, os "nomes nus" só podem ocorrer na posição objeto e não na posição sujeito, como mostra o contraste em (22). Mas, "nomes nus" podem ocorrer numa posição de tópico, quando ligam uma categoria vazia na posição de objeto, mas não na posição sujeito, como mostra o contraste em (23). Como seria de esperar, nas construções com SEindefinido, os "nomes nus" podem ocorrer tanto na posição de objeto, quanto antepostos ao verbo, o que pode provar que esse sintagma esteja na posição periférica, como mostra (24):

(22) a. "O Nestor compra salsichas no talho Sanzot."

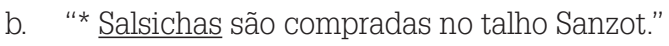

c. " $\quad$ Salsichas custam caro no talho Sanzot."

(23) a. " "Salsichas, o Nestor compra cv no talho Sanzot."

b. " " Salsichas, cv são compradas no talho Sanzot."

c. * Salsichas, cv custam caro no talho Sanzot.

(24) a. "Vendem-se salsichas no talho Sanzot."

b. "Salsichas, vendem-se no talho Sanzot."

Ainda para ilustrar que o DP pré-verbal nas construções com SE-indefinido não ocupa a posição de [Spec, T], mas sim uma posição de tópico e se comporta como um tópico, Raposo e Uriagereka (1996, p. 756) se valem dos seguintes contrastes em (25):

(25) a. " "Consultaram-se os especialistas durante a operação."

b. "Os especialistas consultaram-se durante a operação."

c. "Em que momento da operação os especialistas se consultaram?"

A sentença (25a) recebe uma leitura indefinida. A sentença (25b) é ambígua entre uma leitura indefinida ou reflexiva/recíproca. Já para a sentença (25c), em que ocorre extração do adjunto, só é possível a leitura reflexiva ou recíproca. Isso indica que uma leitura recíproca/reflexiva está associada à posição de [Spec,TP], uma vez que o PP "em que momento" ocorre numa posição mais à esquerda do sujeito.

Raposo e Uriagereka (1996) resolvem a questão da concordância entre verbo e seu argumento interno plural, argumentando que (a) SE é um "DP mínimo", no sentido de possuir traços semânticos reduzidos \{[humano], [indefinido]\}, como $\mathrm{PRO}$ e, portanto, SE checa o traço D de T, e recebe, como PRO, Caso nulo e (b) no $\mathrm{PE}$ existem duas posições disponíveis para checar o nominativo, [Spec, T] e uma outra F. Essa posição F encontra-se à esquerda de T. É nessa posição que o DP argumento interno vai checar o Caso Nominativo. 
Desse modo, a ambiguidade de (25b) se explica a partir da existência de duas análises possíveis para a sentença, como se vê em (26):

(26) a. $\quad\left[_{\mathrm{FP}} \mathrm{OS}\right.$ especialistas $\left[_{\mathrm{F}}\right.$ consultaram $\left[_{\mathrm{TP}} \mathrm{SE}\left[_{\mathrm{T}} \ldots[\right.\right.$ [ ... durante a operação] $\left.\left.\left.]\right]\right]\right]$

b. $\quad\left[_{T P}\right.$ os especialistas [ $\left[_{T}\right.$ consultaram-se [... durante a operação $\left.\left.]\right]\right]$

Essa análise dá conta, portanto, da concordância entre o verbo e seu argumento interno plural, sem postular que o DP esteja na posição sujeito ou ligado a ela. Na verdade, o elemento que ocupa a posição [Spec, T] é o SE, como o SE-nominativo ou SE-genérico (das construções sem concordância).

A proposta de Raposo e Uriagereka (1996) dá conta do PE moderno, desconsiderando a mudança que possa ter ocorrido na história do português que envolve uma mudança de SE-passivo para SE-indefinido. Martins (2003) argumenta que o SE-passivo possui as seguintes características: limitação aos verbos transitivos, concordância obrigatória entre o verbo e o seu argumento interno e expressão opcional do agente da passiva. Essas características, seguindo Naro (1976) estariam ativas até o século XVI, inclusive no que tange à expressão do agente da passiva nas sentenças finitas.

(27) a. "Como Josep se conheceu pelos irmãaos." (NARO, 1976, p.789).

b. "o mar remoto navegamos, que só dos feos focas se navega". (NARO,1976, p.781).

Naro (1976) propõe que na história do português tenha ocorrido uma reanálise gramatical no processo de aquisição em que as sentenças que apareciam sem o agente da passiva expresso foram interpretadas como sentenças ativas e em decorrência disso, surgem as construções sem concordância: a interpretação "impessoal" das construções passivas, segundo Naro (1976), só foi possível pois, (a) na construção com SE-passivo, o agente é opcional; (b) sob determinadas circunstâncias, como para ênfase, o sujeito pode seguir o verbo, constituindo-se uma ordem que ocorre tanto em passivas quanto em ativas, e não tem nenhuma relação especial com a construção com SE-passivo; e (c) em determinados contextos o pronome SE precede seu verbo (é proclítico).

Assim sendo, para Naro (1976) é possível que uma construção com SE-passivo com a forma $\mathbf{S N}_{\mathbf{2}} \mathbf{V}$-se por $\mathbf{S N}_{\mathbf{1}}$ (onde $\mathrm{SN}_{2}$ é o argumento interno, $\mathrm{SN}_{1}$ é o agente da passiva) assuma a forma $\mathbf{s e} \mathbf{V} \mathbf{S N}_{\mathbf{2}}$, que pode ser interpretada como uma sentença ativa: compare-se (27a) com (27b), ambos os exemplos de Naro (1976, p.802-803):

(27) a. "\& porrem se lee este evangelho na festa da trindade."

b. "\& porrem o padre lee este evangelho na festa da trindade." 
Para Naro (1976), são as similaridades entre a ativa e a passiva sem sintagma agentivo expresso e a maior frequência das ativas em relação às passivas (e não a falta de concordância) que fazem com que o falante possa interpretar uma passiva como uma ativa com SE como sujeito. Essa interpretação, no entanto, não seria possível se o sintagma agentivo estivesse de fato presente, uma vez que seria o sujeito semântico.

Os argumentos de Naro (1976) se baseiam, de certo modo, na ordem dos constituintes como sendo um elemento detonador da reanálise: a possibilidade de um sujeito nas sentenças ativas aparecer na posição pós-verbal; a possibilidade de o SE aparecer antes do verbo, o que faz com que o DP argumento interno apareça na posição dos objetos. O problema dessa análise é que para Naro (1976), no século XVI um sujeito pós-verbal é interpretado como sendo um recurso para "ênfase" - como o são os sujeitos pós-verbais do PE atual; e "ocasionalmente" pode ocorrer a próclise do SE, como ocorre no PE atual. Entretanto, os estudos sobre o PCl mostram que a gramática do século XVI é caracterizada por gerar sujeitos pós-verbais com uma frequência maior do que os pré-verbais (GALVES; PAIXÃO DE SOUSA, 2005, 2010); pelos clíticos serem preferencialmente proclíticos, em relação à ênclise, justamente nos contextos de XV, sendo X um elemento não operador de próclise (como um DP ou um PP), como mostram Galves, Britto e Paixão de Sousa (2005).

Desse modo, tanto os sujeitos das construções ativas, quanto os sujeitos das passivas com SE ocupavam a mesma posição no PCl. A reanálise, portanto, ocorre como uma consequência da mudança na posição do sujeito: a partir do momento em que o sujeito passa a posição pré-verbal é que os enunciados com SE passam a ser interpretados como sendo construções ativas e não mais passivas. Voltarei a esse assunto depois de apresentar os padrões estatísticos dos dados.

Retomemos as análises da sintaxe das construções com SE para poder relacioná-la à mudança na posição de sujeito. Por um lado, as propostas que se baseiam somente na concordância entre o verbo e o argumento interno para determinar o caráter passivo das construções com SE ignoram (a) a impossibilidade de aparecer agente da passiva e (b) o fato de o argumento interno, quando anteposto, não ocupar a posição de sujeito, como mostram Raposo e Uriagereka (1996). Por outro lado, a proposta de Raposo e Uriagereka (1996) dá conta da gramática do $\mathrm{PE}$, mas não da gramática do $\mathrm{PCl}$.

Podemos diferenciar três tipos de SE na história do português: o SE-impessoal (ou nominativo, ou genérico), o SE-passivo e o SE-indefinido. O SE-impessoal (ou nominativo, ou genérico) é um argumento, ocupa uma posição argumental e o argumento interno do verbo, quando ocorre, é um objeto. O SE-passivo é um morfema, capaz de mudar a diátese verbal e portanto a atribuição de Caso acusativo e nominativo, e não absorve o papel temático de argumento externo, 
dada a possibilidade de aparecer um PP agente da passiva. As construções de SE-indefinido são estruturas ativas e não passivas, e compartilham com as estruturas sem concordância - se-impessoal - o fato de o SE ocupar a posição de sujeito. O quadro 1 (CAVALCANTE, 2006), a seguir, traz as características dos três tipos de SE:

\begin{tabular}{l|l|l}
\hline \multicolumn{1}{c|}{ Passivo } & \multicolumn{1}{c|}{ Indefinido } & \multicolumn{1}{c}{ Impessoal } \\
\hline Concordância & Concordância & Não concordância \\
DP na posição sujeito & DP na posição sujeito & sem DP na posição sujeito \\
SE é um clítico a Infl & SE ocupa posição sujeito & SE ocupa posição sujeito \\
agente expresso como PP & não possui agente & --- \\
só Verbos transitivos & Verbos transitivos & Todos os verbos \\
\hline
\end{tabular}

Quadro 1 - Tipos de se na história do Português

Fonte: Autoria própria

As propriedades de cada um dos tipos de SE estão relacionadas a propriedades de uma determinada gramática. No caso do SE-passivo, podemos dizer que ele é possível numa gramática que não possui uma posição pré-verbal específica para o sujeito, como numa gramática que possui essa posição. Numa gramática que não tem uma posição pré-verbal específica para o sujeito, o DP argumento interno, quando anteposto, ocupa a posição que os elementos topicalizados ou fronteados ocupam, inclusive um sujeito (PAIXÃO DE SOUSA, 2004; GALVES; PAIXÃO DE SOUSA, 2005, 2010; GALVES; BRITTO; PAIXÃO DE SOUSA, 2005).

Assim, no PCl, uma gramática em que a posição de sujeito era a pós-verbal, os enunciados do tipo Vse DP eram interpretados como sendo VS, pois tanto as construções ativas quanto passivas apresentavam como ordem canônica o sujeito pós-verbal. A evidência para a existência de uma estrutura passiva era a opcionalidade do agente da passiva. A partir do momento em que ocorre uma mudança na estrutura da sentença, e os sujeitos passam a ocupar a posição préverbal, a ordem Vse DP passa a equivaler a uma estrutura Vo, e o agente da passiva não aparece, pois se trata de uma estrutura ativa, e é o que ocorre no PE.

Neste trabalho, apresento uma análise das construções com SE (indefinido e/ ou passivo), em comparação com as passivas analíticas e construções de SE-não passivo. As construções que aqui chamo de SE-não passivo, são os casos que Mateus et al. (2003, p.835-842) classificam como anafóricos (reflexos e recíprocos), como em (28), ergativo/anticausativo, como em (30) e inerente, como em (31): 
(28) a. "Defender-se da influência estrangeira é matar a sua própria cultura - afirma Vargas Llosa."

b. "pro Encontraram-se na Faculdade ao fim da manhã."

(29) "O barco virou-se."

(30) "A Maria apaixonou-se por aquele homem encantador."

Passemos agora à análise estatística dos dados observando os padrões de ordem do DP nas construções com SE passivo/indefinido, SE-não passivo e passivas analíticas na história do português.

\section{A evolução das construções com SE na história: resultados quantitativos}

Foram considerados para análise 19 textos de 18 autores nascidos entre os séculos XVI e XIX pertencentes ao Corpus Tycho Brahe. ${ }^{5}$ Todos os textos estão etiquetados morfologicamente e os dados foram extraídos através de buscas automáticas, o que nos permitiu analisar um universo de 1706 dados. Em seguida, os dados foram codificados e submetidos ao programa Goldvarb X (SANKOFF; TAGLIAMONTE; SMITH 2005) para o controle dos padrões estatísticos. Nesta etapa da pesquisa, estão sendo analisadas somente as sentenças matrizes, mas a etapa de análise das sentenças encaixadas e coordenadas está em andamento. O quadro 2, a seguir, traz a distribuição dos dados por tipo de estrutura: as construções com SE-indefinido/passivo.

\begin{tabular}{|l|l|l|}
\hline & Oco. & $\%$ \\
\hline SE-indefinido/passivo & 895 & 0,52 \\
\hline SE-não passivo & 637 & 0,37 \\
\hline Passivas & 174 & 0,10 \\
\hline Total & 1706 & 1,00 \\
\hline
\end{tabular}

Quadro 2 - Distribuição total dos dados por tipo de construção

Fonte: Autoria própria.

5 Os autores contemplados: Fernão Mendes Pinto (1510-1583), Peregrinação; Diogo do Couto (1542-1606), Décadas; Luis de Sousa (1556-1632), Vida de Frei Bertolameu dos Mártires; F. Rodrigues Lobo (1579-1621), Côrte na Aldeia e Noites de Inverno; Manuel de Galhegos (1597-1665), Gazeta em que se relatam as novas todas que ouve nesta corte; Antonio Vieira (1608-1697), Cartas e Sermões ; J. Cunha Brochado (1651-1735), Cartas; Maria do Céu (1658-1753), Rellaçaõ da Vida e Morte da Serva de Deos a Veneravel Madre Ellena da Crus; Andre de Barros (1675-1754), Vida do apostólico padre Antonio Vieira; Cavaleiro de Oliveira (1702-1783), Cartas; Matias Aires (1705-1763), Reflexão sobre a vaidade dos homens e Carta sobre a Fortuna; Antonio Verney (1713-1792), Verdadeiro Método de Estudar, Antonio da Costa (1714-1780), Cartas do Abade António da Costa; Correia Garção (1724-1772), Obras Completas; Marquesa D'Alorna (1750-1839), Cartas; Almeida Garrett (1799-1854), Viagens na Minha Terra; Marques de Fronteira e Alorna (1802-1881), Memórias do Marquês de Fronteira e Alorna; Ramalho Ortigão (1836-1915), Cartas a Emilia. Os textos estão disponíveis em Corpus (2011). Apresento o sobrenome do autor, seguido da sua data de nascimento quando retiro trechos da obra como exemplo. 
Antes de passar aos resultados, cabe explicar os critérios utilizados para a classificação dos dados que serviram de input para os gráficos. Em primeiro lugar, os dados dos gráficos foram extraídos da Tabela 1, que traz o número total de dados, os valores de anteposição e posposição dos DPs por meio século.

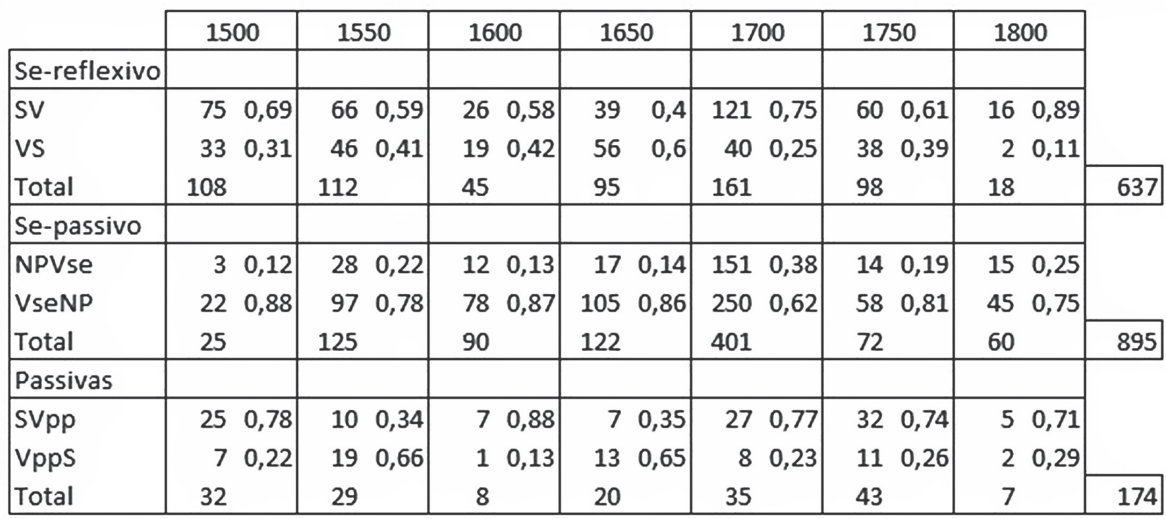

Tabela 1 - Posição do argumento em relação ao verbo em construções com SE indefinido/ passivo, ativas e passivas.

Fonte: Autoria própria.

Todos os gráficos foram elaborados mostrando a evolução da anteposição dos DPs em relação à posposição por tipo de construção e seguem a mesma legenda para o tipo de construção envolvida: "SV" indica a anteposição do DP sujeito de construções ativas (isto é, com outros SE' s: inerente, reflexivo, recíproco e ergativo); "NPVse" indica a anteposição do DP das construções com SE-indefinido/passivo e "SVpp" indica a anteposição do DP sujeito das construções passivas analíticas. A diferença existente entre um SE-passivo e um SE-indefinido está, num primeiro momento, na análise que se faz dos enunciados com SE e com concordância entre o Verbo e seu argumento interno plural: as análises anteriores à de Raposo e Uriagereka (1996) consideram que o argumento interno plural quando anteposto vai para a posição de sujeito; quando posposto, está coindexado à posição de sujeito. Para Raposo e Uriagereka (1996), como foi visto na seção anterior, o argumento interno é um objeto que, quando ocupa a posição pré-verbal, está numa posição de tópico e não de sujeito. Na posição de sujeito se encontra o SE. Desse modo, nos dados diacrônicos, não se pode decidir se estamos diante de um SE-passivo ou SE-indefinido pois superficialmente os enunciados são iguais. Para tomar a decisão teórica acerca de que estrutura(s) estava(m) ativa no PCl e no PE, é necessário ver a evolução do padrão de ordem do argumento interno dessas construções em comparação com os DPs que são inequivocadamente sujeito, como os sujeitos das construções passivas analíticas e das construções ativas (com outros SE's). 
Em segundo lugar, cabe uma nota sobre os padrões de concordância encontrados no CTB, pois é justamente a concordância o critério que se utiliza para diferenciar uma construção passiva sintética de uma construção ativa. Só foi registrado um caso de não concordância entre o verbo e seu argumento interno plural (31a). Foram registrados também casos de não concordância nas sentenças dependentes, como se vê em (31b) a seguir; mas esses casos não foram contados na análise, pois apresento aqui somente os resultados referentes às sentenças matrizes:

(31) a. "Enquanto ao mais o mesmo que em Lisboa e em nada se conhece mais as homogeneidades de raça." - Ramalho Ortigão, 1836. (CORPUS..., 2011).

b. "Considerar a natureza e segui-la é a regra geral para acertar, porém, havendo licença para ornar as cópias que se fazem dela, ajuntando à escolha favorável que se elege os aparatos próprios que se apresentam, pode-se dar alguma liberdade à imaginação, contanto que se não falte à verdade nem ao natural inteiramente." - Cavaleiro de Oliveira, 1702. (CORPUS..., 2011).

Os outros casos em que poderia haver um verbo na $3^{a}$ pessoa do plural foram casos em que a concordância é facultativa, uma vez que se trata de DPs coordenados compostos por núcleos no singular, como ilustrado a seguir (32):

(32) a. Naõ se vio mais pouca vergonha, nem mayor subtileza! - M. da Costa, 1601. (CORPUS..., 2011).

b. Também se acha abutua, e a casca chamada Preciosa. - Andre de Barros, 1675. (CORPUS..., 2011).

c. Pelo rio dos Tocantins se fez esta entrada, e valoroso acometimento - Andre de Barros, 1675. (CORPUS..., 2011).

d. Uma e outra coisa se deve evitar. - Verney, 1713. (CORPUS..., 2011).

O padrão de não concordância que aparece nos dados faz pensar sobre a relevância desse diagnóstico, e somente ele, para determinar o caráter passivo ou não passivo das construções com SE, principalmente se considerarmos a não concordância como um diagnóstico para uma reanálise de SE-passivo em SEnominativo. É por isso que optei por considerar outros fatores sintáticos como diagnóstico para a análise proposta por Raposo e Uriagereka (1996).

O Gráfico 1, a seguir, traz, além das médias de anteposição dos argumentos por metade de séculos e por tipo de construção (em linhas), os percentuais de anteposição por autor (em dispersão). Podemos notar certa variação entre os autores, principalmente nos períodos em que só dispomos de textos de um ou dois autores; entretanto, as curvas com as médias de anteposição indicam as tendências que levantei na primeira seção: um aumento na frequência de anteposição dos DPs sujeitos a partir do século XVIII, que não se verifica nas construções de SE-passivo/indefinido. 


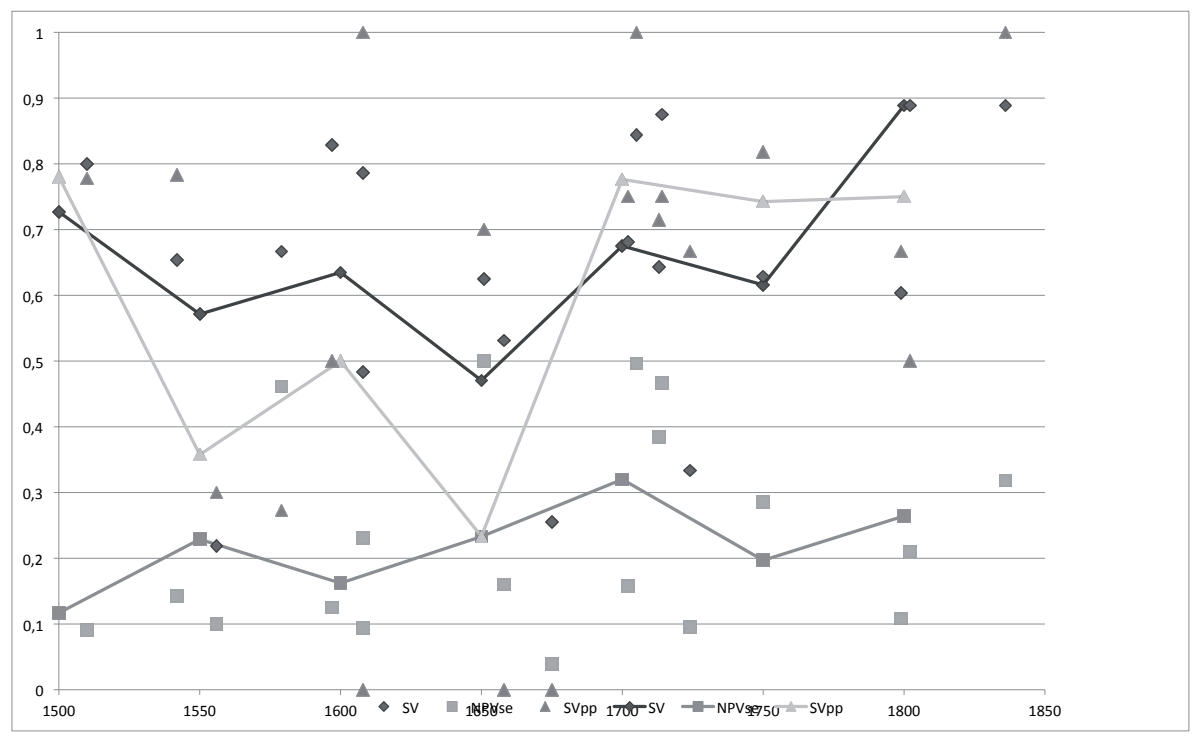

Gráfico 1 - Evolução da anteposição do argumento de construções com SE-indefinido/ passivo, ativas e passivas

Fonte: Autoria própria.

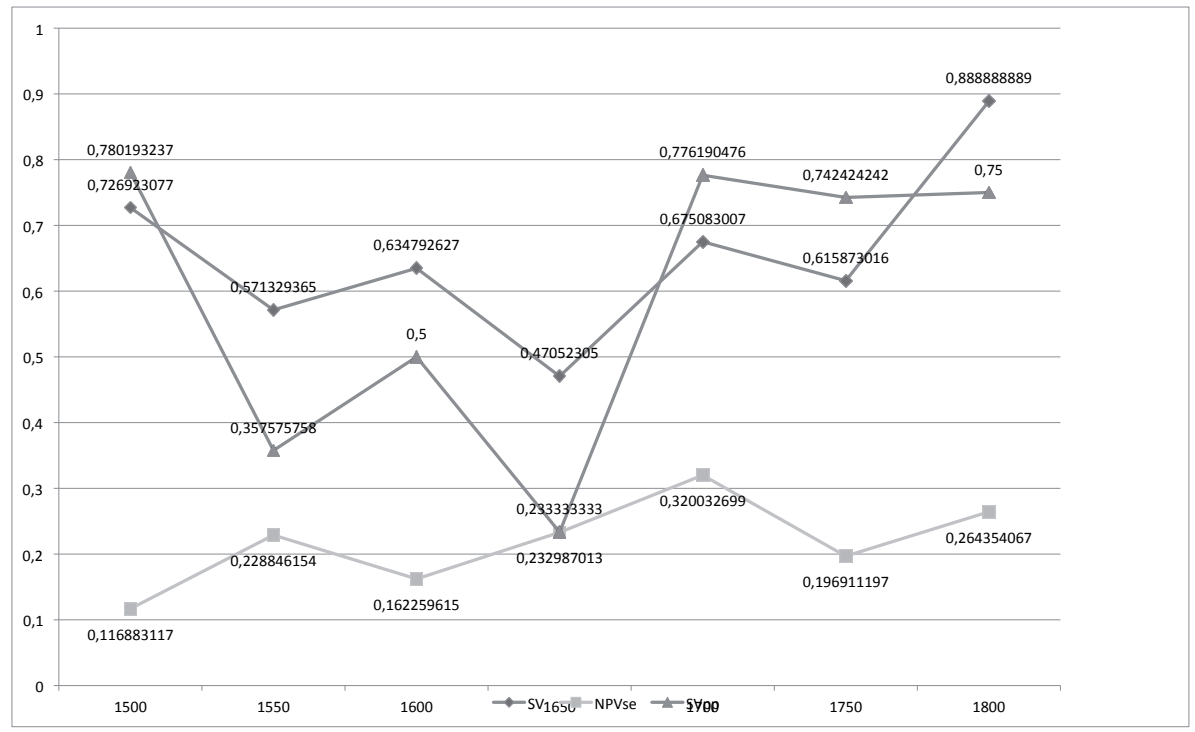

Gráfico 2 - Frequência de anteposição do DP argumento por tipo de estrutura a cada meio século

Fonte: Autoria própria. 
Com o Gráfico 2, que mostra a evolução da anteposição dos DPs ao longo do tempo (por meio século) e por construção, já a mudança fica mais clara: os índices de anteposição dos argumentos nos séculos XVI e XVII se assemelham, nas três construções analisadas, e a partir do século XVIII, as construções que envolvem um DP sujeito apresentam aumento nas frequências de anteposição, enquanto as construções com SE-indefinido permanecem estáveis. Cabe mencionar também os índices de anteposição do DP nas construções com SE oscilam entre 12\% e 32\%, ao passo que o menor índice que anteposição dos sujeitos é 23\%. Há indícios de que, a partir do século XVIII, o DP argumento interno das construções com SE-indefinido quando anteposto, aparece topicalizado.

Esses padrões confirmam as hipóteses levantadas na Apresentação: uma maior semelhança entre as construções passivas e ativas (com SE-não passivo) e as construções com SE-indefinido. A mudança fica mais clara quando consideramos o Gráfico 3 a seguir, que traz agora a evolução por século. Quando temos um maior número de dados (agora agrupados por século), as diferenças que envolvem diferenças nas duas gramáticas e nas construções envolvidas ficam mais claras: a frequência de anteposição do argumento nas construções com SE-indefinido são sempre mais baixas do que as que envolvem a posição do sujeito; além disso, a partir do século XVIII podemos notar, nas construções que envolvem DPs sujeitos, um aumento significativo de frequência de anteposição, diferentemente do que ocorre com o SE-indefinido/passivo. Cabe ainda mencionar que os dados aqui analisados apresentaram índices de anteposição do sujeito sempre superiores ao de posposição, mesmo entre os séculos XVI e XVII, diferentemente dos resultados encontrados por Galves e Paixão de Sousa (2005, 2010) para o mesmo período no mesmo corpus. Isso poderia apontar para uma tendência contrária à esperada para o presente trabalho; entretanto devemos levar em conta que Galves e Paixão de Sousa $(2005,2010)$ não separam o tipo de construção envolvida (passiva, construção com SE, ativa e até construções com verbo cópula), o que pode levar a um índice de posposição maior. Ao separarmos os dados, verificamos a tendência de o DP argumento interno nas construções de SE-indefinido/passivo ocupar a posição de objeto e não de sujeito, isto é, a posição à direita do verbo. 


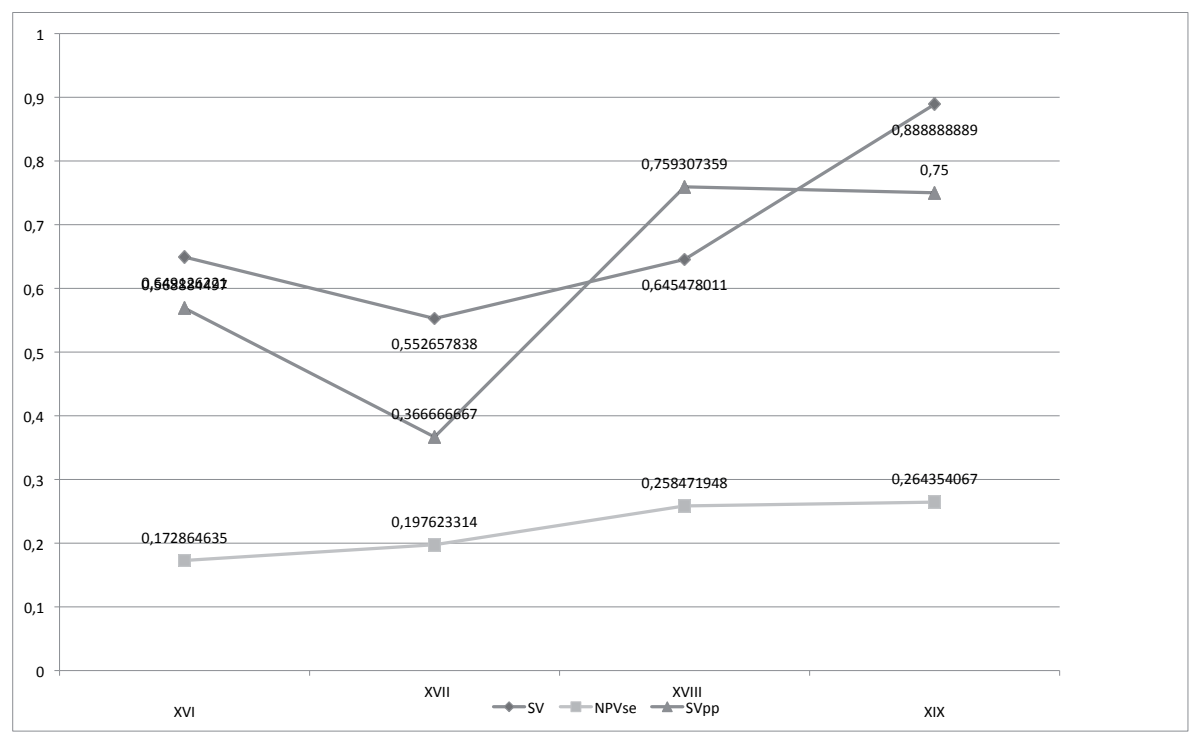

Gráfico 3 - Evolução da anteposição do DP por tipo de construção (média por século) Fonte: Autoria própria.

\section{A questão do encaixamento: mudança na posição do sujeito e mudança no SE?}

Como mencionei anteriormente, os padrões estatísticos indicam o encaixamento da mudança que envolve as construções com SE de passivo para indefinido como estando relacionada à mudança na posição do sujeito. Se a reanálise nas construções com SE de uma passiva para uma ativa ocorreu, como afirma Naro (1976), do século XV para o XVI, então o padrão de anteposição do DP é esperado. Considero aqui que as construções com SE nos textos dos séculos XVI e XVII são uma mistura entre SE-passivo e SE-indefinido: tanto os DPS sujeitos das construções de SE-passivo quando os DPs objetos das construções de SE-indefinido sofrem topicalização quando antepostos. Por isso, não há como diferenciar uma construção da outra, a não ser que haja outro parâmetro para considerar: a presença do agente da passiva. De fato, nos dados até agora analisados, o agente da passiva só aparece em textos de autores dos séculos XVI e XVII, e com frequência muito baixa. A partir do século XVIII, entretanto, considero que as construções de SE-passivo tenham desaparecido, só restando construções de SE-indefinido.

A análise empregada neste trabalho mostrou como se pode depreender a gramática a partir da comparação de padrões estatísticos do comportamento de construções ora consideradas como equivalentes (como o próprio nome 
"passivas sintéticas") ora consideradas diferentes (a oposição entre passiva e ativa nas construções com SE). Os dados mostraram um comportamento mais condizente à análise de Raposo e Uriagereka (1996) em que a taxa de anteposição do DP das construções com SE sempre é mais baixa do que as taxas de anteposição de um DP sujeito "verdadeiro", i.e., um DP que se move para a posição de sujeito ([Spec, T]), pois se trata de anteposição de um objeto. E objetos diretos deslocados possuem uma taxa de anteposição sempre mais baixa do que os sujeitos, seja numa gramática como o $\mathrm{PCl}$, seja numa gramática como o PE, que é SVO.

Os resultados podem ser interpretados seguindo Kroch (2009) que afirma que construções independentes gramaticalmente apresentam padrões estatísticos independentes. De fato, as construções com SE-indefinido não apresentam um comportamento estatístico semelhante às construções que envolvem sujeito, mas podem se aproximar das construções que envolvem topicalização de objeto. A continuação do trabalho se dará justamente na comparação entre as taxas de anteposição do objeto em comparação com posposição do objeto (OV(S) vs. (S)VO).

CAVALCANTE, S. R. O. Statistical patterns of the embedding of the change from passive-SE to indefinite-SE in the history of Portuguese. Alfa, Araraquara, v.55, n.2, p.523-544, 2011.

- ABSTRACT:This paper presents an analysis of so-called passive-SE constructions, compared with canonical passives and other SE-constructions (inherent, reflexive, reciprocal, etc.) in texts written by Portuguese authors born between the 16th and 19th centuries. The aim of this paper is to show that the change from passive-SE into indefinite-SE may be related to the attested change that involves the subject position. According to Galves and Paixão de Sousa (2005, 2010), Classical Portuguese (XVI and XVII centuries) is characterized by being a grammar in which the left position of the verb is a position to where topicalized constituents move, including subjects, so the base position of the subject is post verbal. From the 18th century on, a shift occurs and the subject is preferably pre-verbal and topicalized constituents occupy the left periphery. The quantitative analysis of the evolution of SE-constructions in comparison to canonical passives over time demonstrates that the change that occurs in $S E$-constructions - from passive-SE to indefinite-SE - has have been triggered by the change in subject position.

- KEYWORDS: Quantitative historical syntax. Embedded change. Subject position. Passives. SE-constructions. 


\section{REFERÊNCIAS}

ANTONELLI,A. O clítico SE e a ênclise no Português Clássico. Sínteses, Campinas, v.13, p.29-45, 2008.

CAVALCANTE, S. R. O. O uso de SE com infinitivo na história do Português: do Português Clássico ao Português Europeu e Brasileiro modernos. 2006. 227f. Tese (Doutorado em Linguística) - Instituto de Estudos da Linguagem, Universidade Estadual de Campinas, Campinas, 2006.

CAVALCANTE, S. R. O.; PAIXÃO DE SOUSA, M. C. Subject position and SE constructions in the history of Portuguese. 2009. Trabalho apresentado ao 230 International Conference on Romance Linguistics - Going Romance, Nice, 2009.

CHOMSKY, N. The minimalist program. Cambridge: MIT Press, 1995.

Knowledge of language: its nature, origin and use. London: Praeger, 1986.

CINQUE, G. On si constructions and the theory of arb. Linguistic Inquiry, Cambridge, n.19, p.521-581, 1988.

CORPUS Histórico do Português Tycho Brahe. Disponível em: <http://www.tycho. iel.unicamp.br/ tycho/corpus/index.html>. Acesso em: 15 fev. 2011.

CYRINO, S. M. L. Construções com SE e promoção de argumentos no português brasileiro: uma investigação diacrônica. Revista da ABRALIN, Brasília, v.6, p.85116, 2007.

D'ALESSANDRO, R. Impersonal si constructions. Berlin: Mouton, 2007.

DOBROVIE-SORIN, C. Impersonal si Constructions in Romance and the Passivization of Unergatives. Linguistic Inquiry, Cambridge, n. 29, p.399-437, 1998.

FLORIPI, S. A. Estudo da variação do determinante em sintagmas nominais possessivos na história do português. 2008. 271f. Tese (Doutorado em Linguística) - Instituto de Estudos da Linguagem, Universidade Estadual de Campinas, Campinas, 2008.

GALVES, C. M. C.; BRITTO, H.; PAIXÃO DE SOUSA, M. C. The change in cliticplacement from Classical to Modern European Portuguese: Results from the Tycho Brahe Corpus. Journal of Portuguese Linguistics, Lisboa, v.4, n.1, p.39-67, 2005.

GALVES, C. M. C.; PAIXÃO DE SOUSA, M. C. The loss of verb-second in the history of Portuguese: subject position, clitic placement and prosody. Comunicação apresentada em Diachronic Generative Syntax Conference, 12., Cambridge, 2010.

Clitic placement and the position of subjects in the history of European Portuguese. In: TWAN G.; VAN GINNEKEN, I.; JACOBS, H. (Org.). Romance 
languages and linguistic theory 2003: selected papers from Going Romance 2003. Amsterdam: John Benjamins, 2005. p.97-113.

GIBRAIL, A. V. B. Contexto de formação de estruturas de tópico, foco e adjuntos prepostos no português clássico. 2010. 298f. Tese (Doutorado em Linguística) - Instituto de Estudos da Linguagem, Universidade Estadual de Campinas, Campinas, 2010.

KROCH, A. Making the best use of bad data: some case studies in quantitative historical syntax. Disponível em: <http://www.ling.upenn.edu/ kroch/handouts/ rosae.pdf>. Acesso em: 20 fev. 2011.

MANZINI, M. R. On italian si. In: MANZINI (Org.). Syntax and semantics: the syntax of pronominal clitic. Florida: Academic Press, 1986.

MARTINS, A. M. Construções com SE: mudança e variação no português europeu. CASTRO, I.; DUARTE, I. (Ed.). Razões e emoção: miscelânea de estudos em homenagem a Maria Helena Mateus. Lisboa: Imprensa Nacional, 2003. v.2. p.163-178.

MATEUS, M. H. M. et al. Gramática da língua portuguesa. Lisboa: Caminho, 2003.

MELO, E. A. S. O Estatuto informacional e a posição do sujeito nas passivas analíticas e adjetivas na história do português. In: CONGRESSO NACIONAL DE LINGUÍSTICA E FILOLOGIA, 14., Rio de Janeiro, 2010. Anais... Rio de Janeiro: CiFEFil, 2010. p.2980-2989.

MENDIKOETXEA, A. On the syntax of constructions with arb se in Spanish. Separata de: Anuario del Seminario de Filologia Vasca, [s.1.], v.24, n.1, p.307326,1990 .

NAMIUTI, C. Aspectos da história gramatical do Português: interpolação, negação e mudança. 2008. 331f. Tese (Doutorado em Linguística) - Instituto de Estudos da Linguagem, Universidade Estadual de Campinas, Campinas, 2008.

NARO, A. The genesis of reflexive impersonal in Portuguese. Language, Baltimore, v.52, n.4, p.779-810, 1976.

NUNES, J. M. O famigerado SE: uma análise sincrônica e diacrônica das construções com SE apassivador e indeterminador. 1990. 189f. Dissertação (Mestrado em Linguística) - Instituto de Estudos da Linguagem, universidade Estadual de Campinas, Campinas, 1990. 
OTERO, C. P. Pronombres reflexivos y recíprocos. In: BOSQUE, I.; DEMONTE, V. Gramática descriptiva de la lengua española. Madrid: Espasa Calpe, 1999. p.1427-1517.

PAIXÃO DE SOUSA, M. C. Língua barroca: sintaxe e história do português nos 1600. 2004. 455f. Tese (Doutorado em Linguística) - Instituto de Estudos da Linguagem, Universidade Estadual de Campinas, Campinas, 2004.

RAPOSO, E.; URIAGEREKA, J. Indefinite SE. Natural language and linguistic theory, Dordrecht, v.14, n.2, p.749-810, 1996.

SANKOFF, D.; TAGLIAMONTE, S.; SMITH, E. GOLDVARB X: a multivariate analysis application. 2005. Disponível em: <http://individual.utoronto.ca/tagliamonte/ goldvarb.htm>. Acesso em: 15 fev. 2011.

Recebido em março de 2011.

Aprovado em junho de 2011. 